\title{
Evaluating Douglas-fir and western hemlock volume growth in response to thinning and fertilisation
}

\author{
Gord Nigh
}

\begin{abstract}
Background: Thinning and fertilisation are two silvicultural tools which can modify the growth of a stand. Thinning re-allocates the resources on a site to increase the growth of the trees remaining after the thinning but does not necessarily increase total stand volume as compared to an unthinned stand. Fertilisation is intended to increase the growth of all trees in a stand resulting in more volume. Understanding the response of fertilisation and thinning treatments is critical to making good silviculture prescriptions. To assist with making these prescriptions, yield models for Douglas-fir (Pseudotsuga menziesii (Mirb.) Franco var. menziesii) and western hemlock (Tsuga heterophylla (Raf.) Sarg.) on coastal sites of British Columbia, Canada were developed. Douglas-fir and western hemlock are the two most important species on these sites.

Methods: The data for the modelling came from a large fertilisation and thinning trial (EP703). The model for total volume is based on the Chapman-Richards function. One parameter of the model was expressed as a function of a previous measurement and the other two parameters, which are in turn expressed as a linear function of site index and thinning and/or fertilisation intensity.
\end{abstract}

Results: Independent models were fitted for both species in the study using maximum likelihood estimation. The models were programmed into a spreadsheet to evaluate the behaviour of the models and examine selected responses.

Conclusion: These growth and yield models for Douglas-fir and western hemlock allow forest practitioners to evaluate the outcomes of proposed silviculture prescriptions.

Keywords: Coastal British Columbia; Douglas-fir; Fertilisation response; Modelling; Simulation; Thinning response; Western hemlock

\section{Background}

Thinning and fertilisation are two silvicultural tools available to modify the growth of trees. Thinning is aimed at modifying the growth of a stand by removing trees to adjust the stand density (Smith 1986). While thinning reduces the total volume in a stand, it has the effect of re-allocating the growth resources such as light, moisture, and nutrients to the remaining trees. The intended result is fewer, but larger and more valuable trees. Since thinning reduces stand volume, increases in

\footnotetext{
Correspondence: Gordon.Nigh@gov.bc.ca
}

Forest Analysis and Inventory Branch, British Columbia Ministry of Forests, Lands and Natural Resource Operations, P.O. Box 9512, Stn. Prov. Govt., Victoria, BC V8W 9C2, Canada stand volume over unthinned stands are generally not realized (Smith 1986, p. 129). Fertilisation is intended to increase tree growth. In particular, nitrogen $(\mathrm{N})$ is often the limiting nutrient for tree growth and hence $\mathrm{N}$ enrichment is the most common objective when fertilising forest stands (Bennett et al. 2003). Unlike thinning, a fertilised stand can produce more volume than an unfertilised stand.

Thinning is generally done before crown closure since this is the point when competition is considered to begin and affects the growth of individual trees (Ministry of Forests 1999; Reukema 1975). Once the thinning has been completed, the growth of the remaining trees will accelerate until crown closure is again attained (Hoyer

\section{实}


and Swanzy 1986). The time taken to regain crown closure will depend on the thinning intensity, that is, the amount of volume removed from the stand, and the productivity of the site. The thinned trees can either be utilized (a commercial thinning) or left at the site (a pre-commercial thinning).

Fertilisation can be done anytime during the rotation and a response should be expected. The greatest response may be realized in younger stands when demands for nutrients are high (Chappell et al. 1992; Miller 1981) and also in older stands if $\mathrm{N}$ deficiency exists (Miller 1981).

Douglas-fir (Pseudotsuga menziesii (Mirb.) Franco var. menziesii) and western hemlock (Tsuga heterophylla (Raf.) Sarg.) are the two most common and commercially important species in coastal areas of British Columbia, Canada. In 2011, the total volume of timber harvested on the coast of British Columbia was 19.1 million $\mathrm{m}^{3}$ (approximately $28 \%$ of the total British Columbia harvest), of which $38.2 \%$ was hemlock and $32.6 \%$ was Douglasfir (Ministry of Forests, Lands and Natural Resource Operations 2012).

In order to prepare efficient thinning and fertilisation prescriptions for these species, the effect of the silviculture prescriptions on the yield needs to be known. A growth and yield model that accounts for thinning and fertilisation and their interaction is useful in this regard.

The purpose of this study was to develop empirical growth and yield models that simulate the response (volume growth) to thinning and fertilisation treatments of Douglas-fir and western hemlock stands. The models can then be used to evaluate different thinning and fertilisation strategies to gain a better understanding of responses of these species to these treatments. The literature reports many different, and sometimes conflicting, responses to thinning and fertilisation. The models that are developed and described here will allow the responses of Douglas-fir and western hemlock on coastal areas of British Columbia to be explored. Western hemlock and Douglas-fir growth after thinning and/or fertilisation can be assessed and better understood with the models.

The modelling approach of Nishizono (2010) was closely followed. This seemed to be an expedient method of analysis since the Nishizono (2010) model fit the data well. It is also possible to implement the model in a spreadsheet, making it available from the published report without requiring specialized software. The liberty of making some modifications to Nishizono's work to get a better fitting model was taken. The model was also modified to incorporate both thinning and fertilisation and their interaction. This increased the utility of the model and allowed it to explicitly simulate thinning and fertilisation treatments as interacting responses. Because the models are relatively simple, the responses can be evaluated analytically to some degree by examining the parameter estimates and can be more fully explored graphically.

\section{Methods \\ Data}

The data for this study come from Experimental Project 703 (EP703). This project is a large thinning and fertilisation trial established on the coast of British Columbia to examine the growth response of Douglas-fir and western hemlock to thinning and fertilisation (Darling and Omule 1989; Stone 1994). This study was initiated in 1971 and eventually encompassed 940 plots at 85 installations. Only plots that were pure Douglas-fir or pure western hemlock were analyzed, leaving 486 Douglas-fir plots and 222 western hemlock plots available for analysis. The plots were located in the Coastal Western Hemlock biogeoclimatic zone, xm1 (very dry maritime), xm2 (very dry maritime), vm1 (very wet maritime), ds1 (dry submaritime), and dm (dry maritime) subzone variants (Green and Klinka 1994). Installation locations and more specific plot information can be found in Stone (1994). Table 1 presents summary information about the plots at their first and last measurement.

The thinning treatments ranged from controls $(0 \%$ removal) up to $50 \%$ removal. All but two of the thinned plots (one for each species) were thinned to maintain the thinning ratio (mean diameter of removed stems over the mean diameter of stems before thinning) at $0.8-0.9$ (Darling and Omule 1989; Stone 1994). The other two thinned plots were thinned to 746 stems per hectare (Stone 1994). Fertilisation was applied at rates of $225,450,675$, or $900 \mathrm{~kg} / \mathrm{ha}$ with prilled urea $(46 \%$ nitrogen, Darling and Omule 1989). The application was done manually except for 43 Douglas-fir plots which were fertilised aerially.

The total age (yrs), total standing volume $\left(\mathrm{m}^{3} / \mathrm{ha}\right)$, and volume $\left(\mathrm{m}^{3} / \mathrm{ha}\right)$ removed through thinning were available for each species in the plot at each measurement. Only trees that had a diameter at breast height of $5.0 \mathrm{~cm}$ or greater were measured. Since only pure Douglas-fir and western hemlock stands were of interest, a plot was classified as being pure Douglas-fir (pure western hemlock) if it contained 80\% Douglas-fir (western hemlock) by volume, averaged over all measurements. However, regardless of the species composition, the total volume of all species in the plot was analyzed. The site index $(\mathrm{m}$ at breast height age 50) was estimated from the height and age of the target species using the Bruce (1981) or Wiley (1978) height-age models for Douglas-fir and western hemlock, respectively. 
Table 1 Summary information for the first and last measurements of the study plots

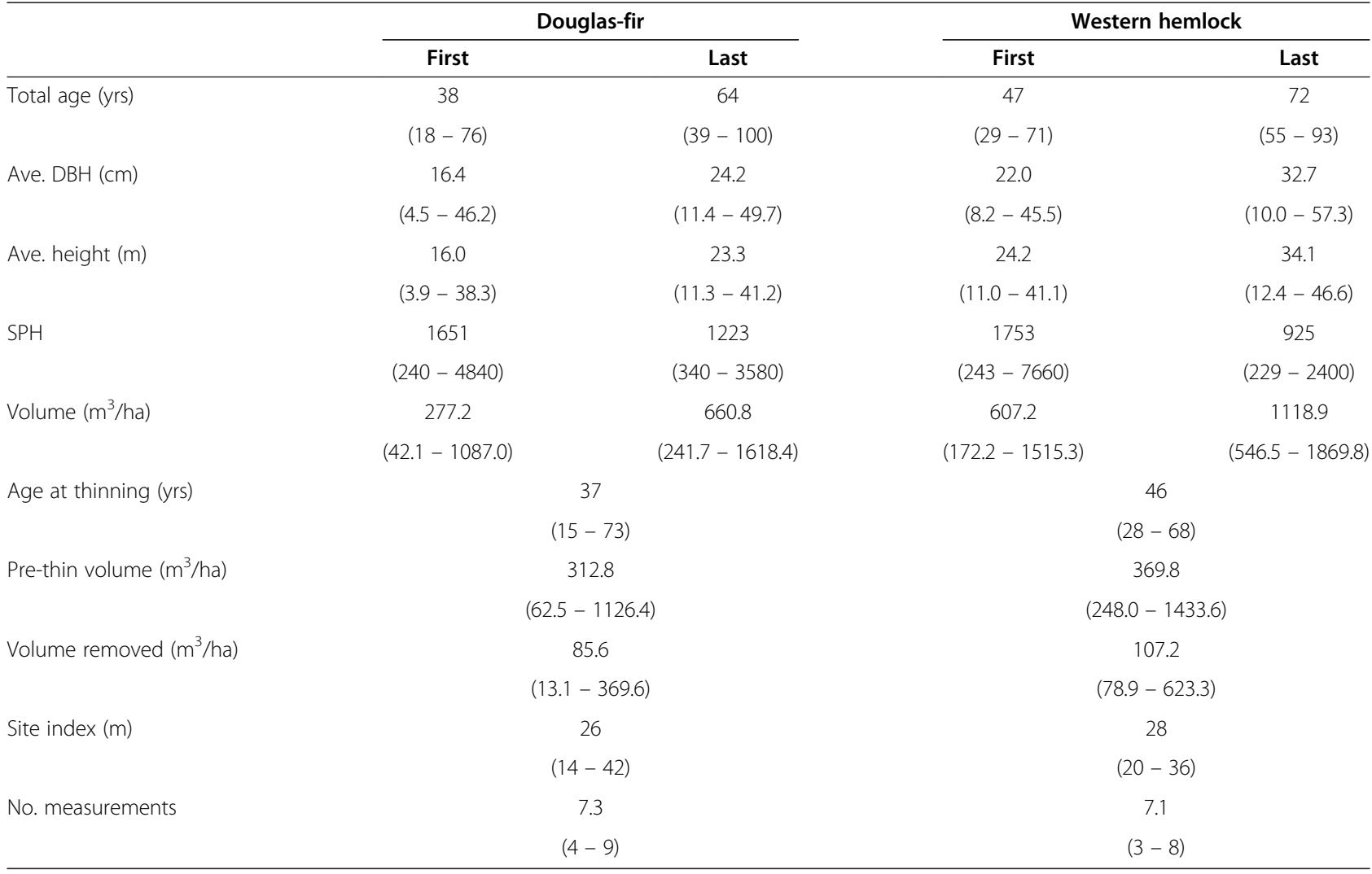

DBH is diameter at breast height. SPH is stems per hectare. The average for the variable is presented with values in parenthesis indicating the range for the variable. The thinning statistics are for the thinned plots only.

\section{Modelling}

The modelling generally follows the procedure taken by Nishizono (2010). The base model is the ChapmanRichards function (Richards 1959):

$$
\mathrm{V}_{\mathrm{i}}=\mathrm{b}_{0}\left(1-\mathrm{e}^{-\mathrm{b}_{1} \times \mathrm{t}_{\mathrm{i}}}\right)^{\frac{1}{1-\mathrm{b}_{2}}}
$$

where $V_{i}=$ standing total live volume $\left(\mathrm{m}^{3} / \mathrm{ha}\right)$ at age $t_{i}$ yrs, e is the base for natural logarithms, $b_{0}, b_{1}$, and $b_{2}$ are model parameters, and i indexes the measurement for a plot. By algebraically manipulating Equation 1 (Bailey and Clutter 1974), parameter $b_{1}$ was expressed as a function of a known volume $\mathrm{V}_{\mathrm{i}-1}\left(\mathrm{~m}^{3} / \mathrm{ha}\right)$ at age $\mathrm{t}_{\mathrm{i}-1}$ yrs and parameters $b_{0}$ and $b_{2}$. In this analysis, $V_{i-1}$ and $t_{i-1}$ are the volume and age at the previous measurement.

$$
\mathrm{b}_{1}=-\frac{\ln \left(1-\left(\mathrm{v}_{\mathrm{i}-1} / \mathrm{b}_{0}\right)^{1-\mathrm{b}_{2}}\right)}{\mathrm{t}_{\mathrm{i}-1}}
$$

where $\ln$ is the natural logarithm. Substituting Equation 2 into Equation 1 for $b_{1}$ and adding a random error term $\left(\varepsilon_{\mathrm{i}}\right)$ yields Equation 3:

$$
\mathrm{V}_{\mathrm{i}}=\mathrm{b}_{0}\left\{1-\left[1-\left(\mathrm{V}_{\mathrm{i}-1} / \mathrm{b}_{0}\right)^{\left(1-\mathrm{b}_{2}\right)}\right]^{\mathrm{t}_{\mathrm{i}} / \mathrm{t}_{\mathrm{i}-1}}\right\}^{\frac{1}{1-\mathrm{b}_{2}}}+\varepsilon_{\mathrm{i}}
$$

Similarly to what Nishizono (2010) did, the remaining two parameters, $b_{0}$ and $b_{2}$, were expressed as functions of site index, thinning regime, and fertilisation regime:

$$
\begin{aligned}
\mathrm{b}_{0}= & \mathrm{b}_{00}+\mathrm{b}_{01} \times \mathrm{SI}+\mathrm{b}_{02} \times \mathrm{T}+\mathrm{b}_{03} \times \mathrm{F}+\mathrm{b}_{04} \\
& \times \mathrm{T} \times \mathrm{F}+\mathrm{b}_{05} \times \mathrm{SI} \times \mathrm{T}+\mathrm{b}_{06} \times \mathrm{SI} \times \mathrm{F} \\
\mathrm{b}_{2}= & \mathrm{b}_{20}+\mathrm{b}_{21} \times \mathrm{SI}+\mathrm{b}_{22} \times \mathrm{T}+\mathrm{b}_{23} \times \mathrm{F}+\mathrm{b}_{24} \\
& \times \mathrm{T} \times \mathrm{F}+\mathrm{b}_{25} \times \mathrm{SI} \times \mathrm{T}+\mathrm{b}_{26} \times \mathrm{SI} \times \mathrm{F}
\end{aligned}
$$

where $\mathrm{SI}=$ site index ( $\mathrm{m}$ at breast height age 50$), \mathrm{b}_{\mathrm{ij}}, \mathrm{i}=$ $1,2, j=0,1, \ldots, 6$ are model parameters, $T$ is thinning intensity, $\mathrm{F}$ is fertilisation intensity, and $\varepsilon$ is a random error term with the usual assumption that the $\varepsilon$ are identically and independently distributed as $\mathrm{N}\left(0, \sigma^{2}\right)$. Thinning intensity $(\mathrm{T})$ is the volume $\left(\mathrm{m}^{3} / \mathrm{ha}\right)$ removed divided by the time (years) since the thinning. Fertilisation intensity (F) is the amount of fertiliser applied ( $\mathrm{kg} / \mathrm{ha})$ divided by the time (years) since fertilisation. 
Three significant modifications to Nishizono's (2010) model and analysis were made: modifying the definition of thinning intensity, adding fertilisation, and analyzing the models as marginal or population average models (Diggle et al. 2002). These modifications are discussed more extensively in the Discussion section.

Mortality is not explicitly modelled. The dependent variable, standing live volume $\left(\mathrm{V} \mathrm{m}^{3} / \mathrm{ha}\right)$, is net of mortality. Therefore, the model implicitly incorporates endemic mortality. If catastrophic mortality events such as massive windthrow or insect attack occur, then the models cannot be expected to give reasonable volume predictions. Since only endemic mortality was included in the model, data for which there was evidence of catastrophic volume loss was removed from the analysis data set.

Maximum likelihood estimation (procedure NLMIXED in SAS, SAS Institute Inc. 2004) was used to fit the model to the data. The variance was modelled as a power of the time since the last measurement (Pinheiro and Bates $2000)$, i.e., $\operatorname{Var}\left(\varepsilon_{\mathrm{i}}\right)=\sigma^{2}\left(\mathrm{t}_{\mathrm{i}}-\mathrm{t}_{\mathrm{i}-1}\right)^{2 \delta}$. Serial correlation should not be an issue since volume is being projected for only one measurement interval. For each measurement in each plot, the standing volume $\left(\mathrm{V}_{\mathrm{i}} \mathrm{m}^{3} / \mathrm{ha}\right)$ was the dependent variable and the total age ( $t_{i}$ years) and the standing volume $\left(\mathrm{V}_{\mathrm{i}-1}\right)$ and total age $\left(\mathrm{t}_{\mathrm{i}-1}\right)$ from the previous measurement were independent variables in the fitting process, as well as the other variables in Equation 4. Consequently, the volume from the first observation for each plot was not used as a dependent variable since there was not a previous measurement to provide a value for $V_{i-1}$ and $t_{i-1}$. For all plots except one Douglas-fir plot, the thinning was done immediately after the plot was established. Therefore, the post-thinning volume (as opposed to the pre-thinned volume) was considered to be the observation for that year except for the one plot where the thinning was not done at plot establishment. For this plot, the pre-thinned volume was used as $V_{i}$ for that year. The post-thinning volume was obtained by subtracting the volume removed in the thinning from the pre-thinned volume and it was used as $\mathrm{V}_{\mathrm{i}-1}$ for the next observation. Each species was analyzed independently from the other. Normal quantile-quantile (QQ) plots of the standardized residuals were made to check for normality and plots of the standardized residuals versus the fitted values and the years since the previous measurement $\left(t_{i}-t_{i-1}\right)$ were made to check that the residuals were homoscedastic (Sen and Srivistava 1990).

\section{Simulation}

Simulations were performed to assess the behaviour of the model and to test specific responses as reported in the literature. This will help clarify expected responses that may be unclear or in some cases conflicting. There are too many parameters that can be varied, such as starting volume and age, site index, age and intensity of the thinning and fertilisation treatments, to fully assess the model. Instead, a few starting values for the parameters were selected and used in the simulations to demonstrate how the models can be used. The fitted models for Douglas-fir and western hemlock were programmed in a spreadsheet. Table 2 shows the input parameters for the simulations. The volume removed by the thinning itself is explicitly simulated through the variable $\mathrm{V}_{\mathrm{i}}$. For example, if the thinning occurs in year $\mathrm{T}$ then the simulation is run until year $T$ resulting in volume $V_{i}$. To predict volume for the next period, variable $V_{i-1}$ is set equal to $V_{i}$ less the volume thinned and $t_{i-1}$ is set equal to $\mathrm{T}$ and the projection continues from that point. The simulation runs result in predicted standing volume (volume of all live standing trees) by age.

\section{Results \\ Modelling}

The results of the analysis of Equation 3 with parameters given in Equation 4 are presented in Table 3. The power parameter for the weights $(\delta)$ was 0.8162 for Douglas-fir and 0.6806 for western hemlock. Parameter $\sigma$ in the variance model was 5.602 for Douglas-fir and 9.153 for western hemlock, although these values are hard to interpret on their own since the weights also have to be considered to fully understand the error structure. The QQ plots showed slight non-normality in the standardized residuals for Douglas-fir but the western hemlock standardized residuals were normal. There was no evidence

\section{Table 2 Input parameters used in the simulation runs}

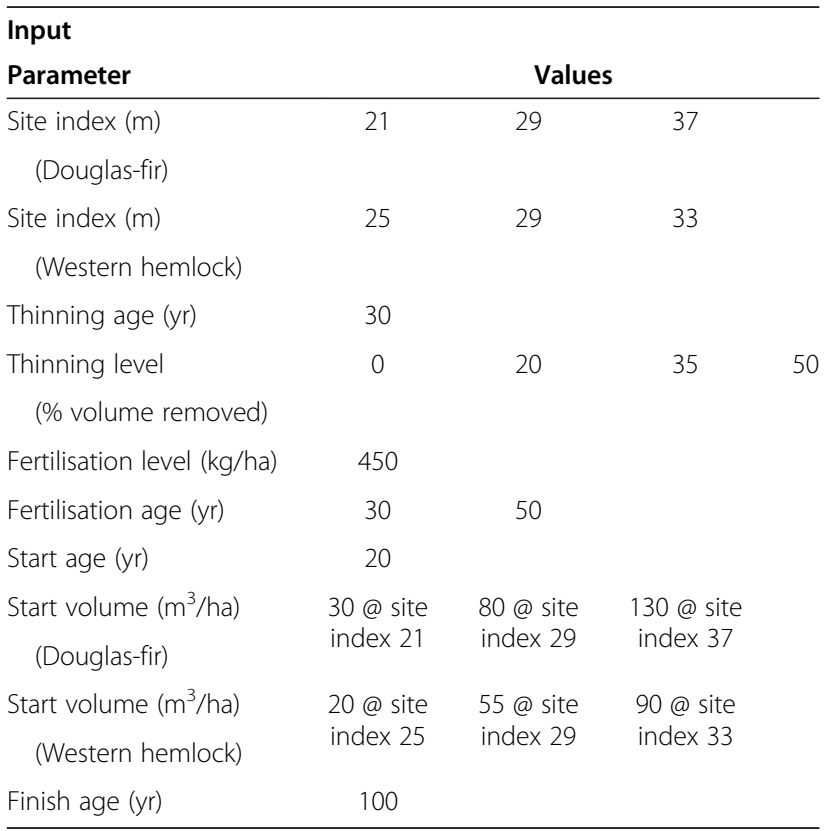


Table 3 Results of the analysis of model 3 for Douglas-fir and western hemlock

\begin{tabular}{|c|c|c|c|}
\hline \multirow[b]{2}{*}{ Species } & \multicolumn{3}{|c|}{ Parameter } \\
\hline & Parameter & Estimate & Std. Err. \\
\hline \multirow[t]{12}{*}{ Douglas-fir } & $b_{00}$ & -906.7 & 116.3 \\
\hline & $b_{01}$ & 88.23 & 4.707 \\
\hline & $b_{02}$ & -175.1 & 23.92 \\
\hline & $b_{03}$ & 21.40 & 3.803 \\
\hline & $b_{04}$ & 6.376 & 1.075 \\
\hline & $b_{05}$ & 11.92 & 1.450 \\
\hline & $b_{06}$ & -0.6717 & 0.1054 \\
\hline & $b_{20}$ & 0.8412 & 0.02315 \\
\hline & $b_{21}$ & -0.007438 & 0.0008311 \\
\hline & $b_{22}$ & -0.001296 & 0.0001893 \\
\hline & $b_{23}$ & 0.0004199 & 0.00004177 \\
\hline & $b_{24}$ & -0.000007131 & 0.000001324 \\
\hline \multirow[t]{9}{*}{ Western hemlock } & $b_{00}$ & -895.1 & 189.6 \\
\hline & $b_{01}$ & 92.84 & 7.214 \\
\hline & $b_{02}$ & 148.9 & 14.14 \\
\hline & $b_{04}$ & -0.1918 & 0.01657 \\
\hline & $b_{05}$ & -0.9547 & 0.3268 \\
\hline & $b_{20}$ & 1.355 & 0.04396 \\
\hline & $b_{21}$ & -0.02524 & 0.001689 \\
\hline & $b_{23}$ & 0.0002371 & 0.00006200 \\
\hline & $b_{25}$ & -0.00006663 & 0.000007122 \\
\hline
\end{tabular}

Parameter estimates that were significantly different from 0 at $\alpha=0.05$ are presented. Other parameters are not in the model and hence have a value of 0 . Parameter estimates and their standard errors are shown to 4 significant digits.

of heteroscedasticity for both species, indicating that the variance structure was adequately modelled.

\section{Simulation}

The results of the simulations for selected scenarios are discussed in the following section.

\section{Discussion}

This research results in models that predict stand volume after thinning and fertilisation for Douglas-fir and western hemlock on the coast of British Columbia. The predictions are made from stand volume at a known age, target age of the predicted volume, site index, and thinning and fertilisation intensity. Thinning intensity is defined as volume $\left(\mathrm{m}^{3} / \mathrm{ha}\right)$ removed in the thinning divided by the time since thinning. Fertilisation intensity is similarly defined as the amount of urea fertiliser ( $\mathrm{kg} / \mathrm{ha}$ ) applied divided by the number of years since the application. Therefore, the effect of both thinning and fertilisation on volume growth decreases over time. The models that were developed are dynamic in the sense of Diéguez-
Aranda et al. (2006). That is, model predictions are based on a known volume/age point $\left(\mathrm{V}_{\mathrm{i}-1}, \mathrm{t}_{\mathrm{i}-1}\right.$ in Equation 3), which is then projected forwards or backwards in time. The models are path invariant which means that the projections from age $t_{i-1}$ to age $t_{1}$ can be made in a single time step or multiple time steps and the same predicted volume will be obtained (Diéguez-Aranda et al. 2006).

This work closely follows that of Nishizono (2010), the major difference being the definitions of thinning intensity and the addition of fertilisation. Analyzing the models using a thinning intensity defined as the volume removed in a previous thinning, as was used by Nishizono (2010) resulted in a poorer fit. The definition of thinning intensity that was implemented (volume removed divided by time since thinning) results in the effect of the thinning in the model dwindling over time. The stands in the data set were only thinned once; hence only one thinning was modelled. It is not intuitive how to modify the implemented thinning intensity definition for multiple entries. Two options are to either accumulate the thinning intensities or to calculate the thinning intensity as if a previous thinning had not been done. The two methods would give similar results if the thinnings are far apart in time.

Similarly for fertilisation, the variable F (fertilisation intensity) is the amount of fertiliser applied ( $\mathrm{kg} / \mathrm{ha}$ ) divided by the time (years) since fertilisation. This allows the growth rate to increase rapidly after fertilisation but over time the effect of fertilisation dissipates.

Unlike Nishizono (2010), who analyzed the thinning model as a nonlinear mixed-effects model, the model was fitted as a nonlinear population-average model. The response (volume) of the population average was of more concern than predicting the response of individuals, making the population-average model more appropriate (Diggle et al. 2002, p. 130). Furthermore, in application it is unlikely that there will be enough measurements to adequately calibrate a mixed-effects model. Unlike linear models, a nonlinear mixed-effects model with the random parameters set to their expected value of 0 does not give unbiased estimates of the population mean (Meng and Huang 2009, p. 245). Hence, in the situation where the model will not be calibrated for individuals, it is preferable to fit the model as a population-average model.

In the data analysis, the models project the volume for one measurement only resulting in short projection periods. Consequently, evaluating the residuals from the analysis does not give a good indication of model performance over a long period of time, as would be useful in a real application. A more pragmatic test was performed by projecting the volumes with the first post-treatment observation (or first observations for the control plots) and examining the residuals from 
these projections. This was done for the control plots and plots that only had one treatment in order to isolate the model behaviour by treatment type. The residual variance increased as the length of the projection period increased as is typical in yield projections. The control plots did not show any bias over the projection period, nor did the fertilised western hemlock plots. The thinned Douglas-fir plots and the fertilised Douglasfir plots each showed a bias of about $1 \mathrm{~m}^{3} / \mathrm{ha} / \mathrm{yr}$ and the thinned western hemlock plots had a bias of less than $2 \mathrm{~m}^{3} / \mathrm{ha} / \mathrm{yr}$. These biases are small but nevertheless could be an area of future refinement to the models. In practice, periodic stand volume measurements could be taken and used as input to the model to reduce the length of future stand volume projections.

The starting parameters for the site index, start and finish ages, and thinning levels in the simulations (Table 2, Figures 1, 2, 3 and 4) were chosen to cover the range of the data. The initial volumes were obtained from runs of the Tree And Stand Simulator (TASS) growth and yield model (Mitchell 1975; Mitchell and Cameron 1985). Although the 100-year end time for the simulations is longer than typical rotation ages for Douglas-fir and western hemlock in coastal British Columbia (Brown 2003; Spittlehouse 2003), it may be informative to investigate the response to thinning and/ or fertilisation over this longer time horizon.

Interpreting the effect of parameters $b_{0}$ and $b_{2}$ on model behaviour is somewhat complicated by the formulation. This is an artefact of parameter $b_{1}$ in Equation 1 being a function of parameters $b_{0}$ and $b_{2}$. Parameter $b_{0}$ in Equations 1 and 3 is the asymptote; hence larger values of $b_{0}$ indicate a greater potential volume from the site. Parameter $b_{2}$ is indicative of the growth rate of the stand with higher values indicating faster growth.

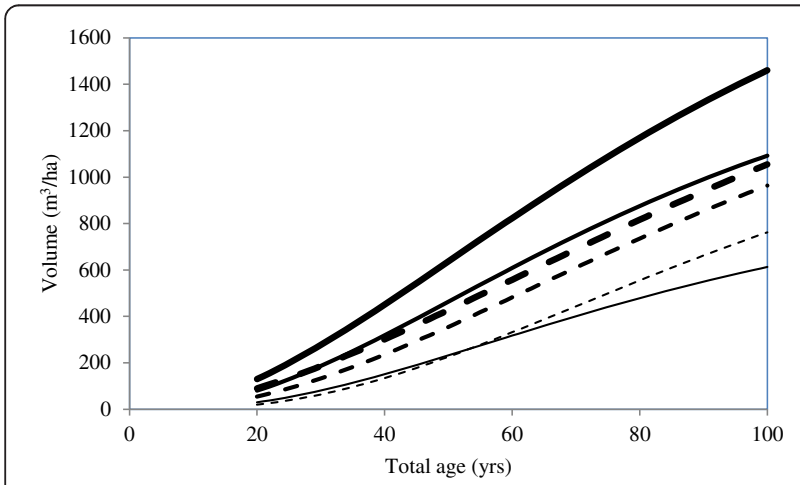

Figure $1 \mathrm{Graphs}$ of stand volume $\left(\mathrm{m}^{3} / \mathrm{ha}\right)$ versus total age for Douglas-fir and western hemlock. Volume trajectories at three levels of site index are shown. No thinning or fertilisation was simulated. Douglas-fir site index 21: — Douglas-fir site index 29: — Douglas-fir site index 37: western hemlock site index 25: - - - ; western hemlock site index 29: - - ; western hemlock site index 35: $\mathbf{m}$
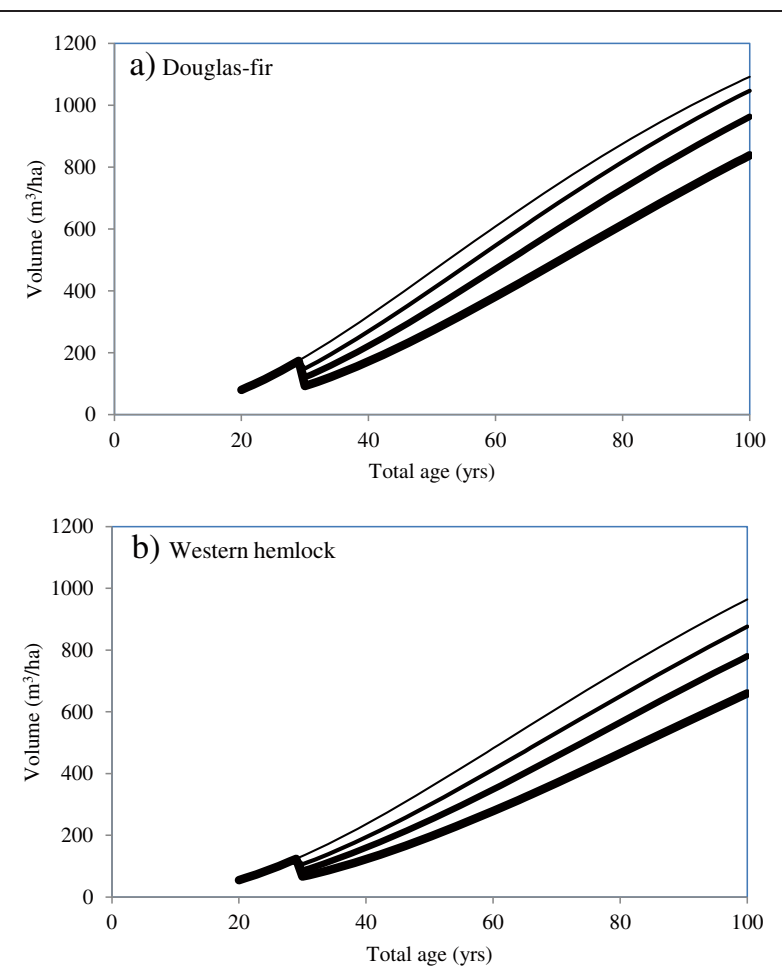

Figure 2 Graphs of stand volume $\left(\mathrm{m}^{3} / \mathrm{ha}\right)$ versus total age for Douglas-fir (a) and western hemlock (b). Volume trajectories are shown for four levels of thinning at a site index of $29 \mathrm{~m} .0 \%$ removal:_; $20 \%$ removal: $=; 35 \%$ removal: $; 50 \%$ removal:

However, a graphical approach has to be taken to fully assess the behaviour of the models because of the interaction between parameters $b_{0}$ and $b_{2}$ in Equations $3 / 4$.

Snowdon (2002) classifies growth responses to silvicultural treatments as being a type 1 or type 2 response. Type 1 responses are characterized by a temporary increase in growth rate that reduces the time needed to reach a given stage of stand development. Type 2 responses are characterized by a real and sustained change in stand productivity. The response to fertilisation can be either type 1 or type 2, depending on the amount of fertiliser and the nutrient deficiency of the site (Snowdon 2002). Thinning will most likely be a type 1 response since the volume of a thinned stand rarely exceeds the volume of an unthinned stand, although the response to thinning may be sustained for quite a while. Given the model formulation in Equations 3/4, the response to both fertilisation and thinning dwindles over time making the response a type 1 response. Simulations using average start values in Table 2 confirm that both thinning and fertilisation are type 1 responses for western hemlock and Douglas-fir. Initially, fertilisation increases growth and thinning decreases stand growth but over time the stand growth for both treatments converge to the growth of the untreated stand. Note, however, that an extreme 


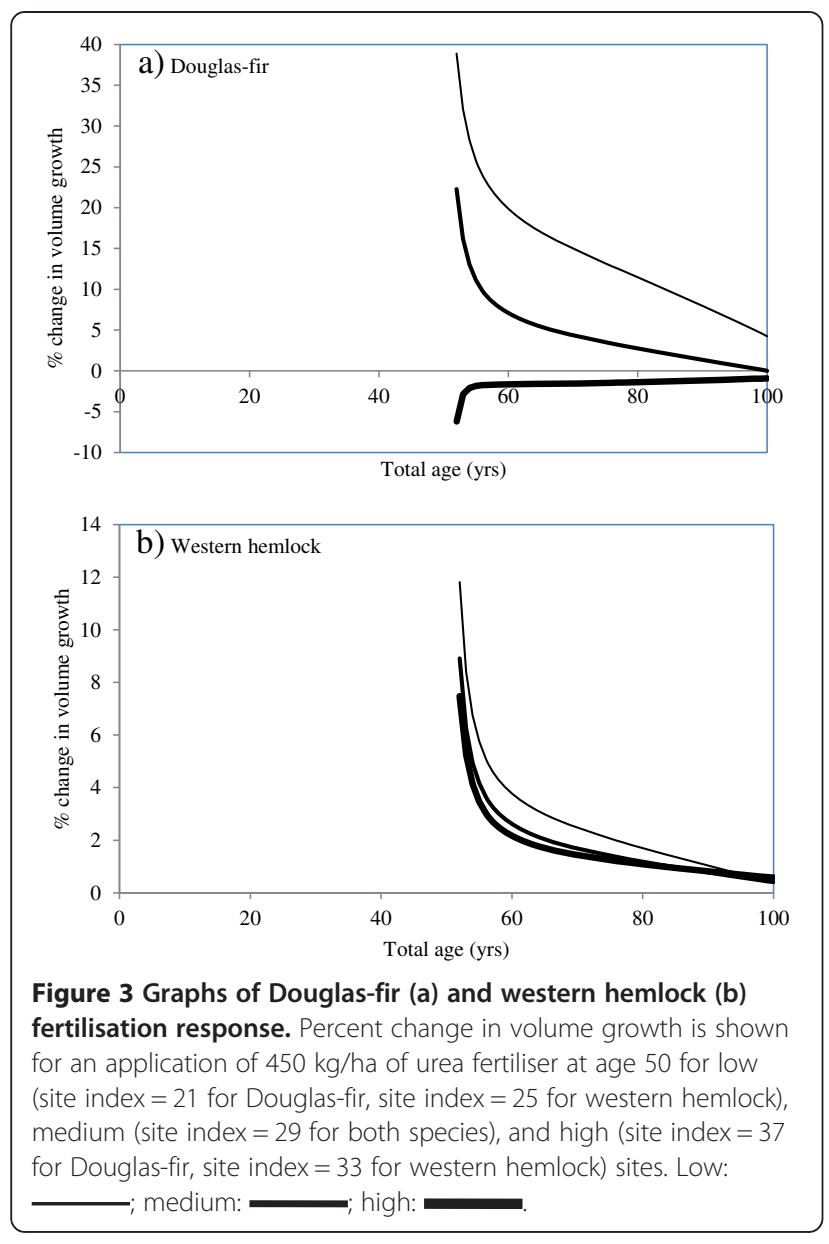

thinning will reduce the volume to a point where the growth of the treated stand diverges from the growth of the untreated stand over a typical rotation period.

The response of Douglas-fir and western hemlock to thinning and fertilisation can now be compared to published responses using these new models. This is done in part to assess the integrity of the model and to evaluate specific responses. The assessment is done analytically by examining the parameters of the model (Equation 4) but mostly by using graphical techniques.

\section{More productive sites (higher site index) have increased growth and yield}

Site index is a measure of site productivity; better sites produce a greater volume of timber and the trees on the site are faster growing (Carmean 1975). Parameter $b_{0}$ increases and parameter $b_{2}$ decreases with site index for both species. As gleaned from the value of parameter $\mathrm{b}_{0}$, the potential yield (asymptote) increases as site index increases. A graphical analysis (Figure 1) shows that growth also increases as site index increases even though parameter $b_{2}$ decreases. The models behave as expected with respect to site index.
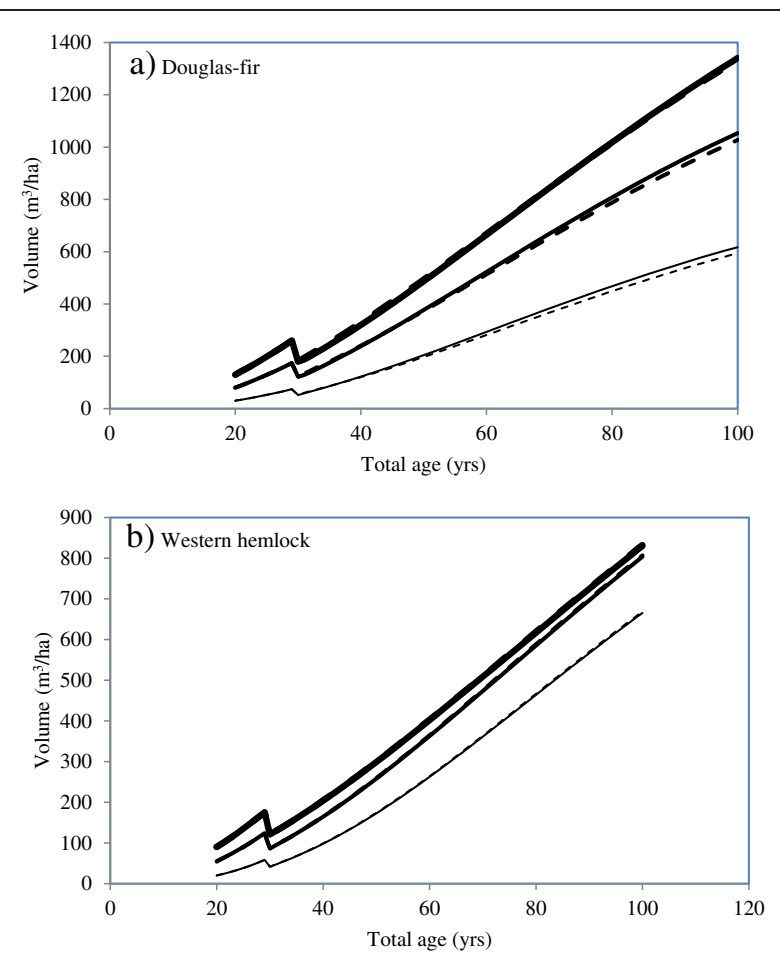

Figure 4 Effect of the fertilisation $\times$ thinning interaction on volume for Douglas-fir (a) and western hemlock (b). Volume trajectories are shown for thinning (35\% removal) and fertilisation ( $450 \mathrm{~kg} / \mathrm{ha}$ ) treatments applied at age 30 for low (site index $=21$ for Douglas-fir, site index $=25$ for western hemlock), medium (site index $=29$ for both species), and high (site index $=37$ for Douglas-fir, site index $=33$ for western hemlock) sites, with and without the interaction term. Low, with interaction: medium, with interaction: w/o interaction: - - - - ; medium, w/o interaction: - - ; high, w/o interaction:

The response to thinning depends on the thinning intensity On a per tree basis, a heavy thinning will reduce competition more than a lighter thinning and hence the growth response is expected to increase as the thinning intensity increases (Pukkala et al. 2002). However, on a stand level the response is less clear because there are fewer trees to contribute to stand growth. Cañellas et al. (2004) found that Quercus pyrenaica growth increased with increasing thinning intensity but declined with the heaviest thinning. D'Amato et al. (2011) did not find any stand-level growth response to thinning of Picea glauca stands. For Pinus sylvestris stands, stand volume increment decreased as thinning intensity increased and the difference increased over time (del Río et al. 2008). To evaluate the fitted models, volume was plotted against age at 4 levels of thinning that occurred at age 30 assuming a site of medium quality (site index $=29 \mathrm{~m}$ ) for both species (Figure 2). In absolute terms, the volume in the thinned stands did not approach the volume in the unthinned stands. That is, the volume lost in the thinning 
was not recovered through increased growth of the trees left on the site. However, on a relative basis, the thinned stands had proportionally more volume at the end of the 100 year simulation than was removed. That is, for Douglas fir, the volume lost when compared to the unthinned stands was $4 \%, 12 \%$, and $23 \%$ for the $20 \%$, $35 \%$, and $50 \%$ removals, respectively. The volume lost for western hemlock was $9 \%, 19 \%$, and $32 \%$ for the same levels of removal.

\section{The effect of fertilisation on tree growth is relatively short-lived}

Nitrogen $(\mathrm{N})$ is the most limiting nutrient in Douglas-fir and western hemlock sites (Bennett et al. 2003; Chappell et al. 1991). Consequently, fertilisation with $\mathrm{N}$ is more common than fertilising with other nutrients. The period of time for which tree growth is elevated after fertilisation is variable but relatively short, e.g. 5 - 10 years (Bennett et al. 2003; Binkley and Reid 1985), although exceptions can be found (Binkley and Reid 1985). When fertiliser is applied at the time of thinning the maximum response is observed about 5 years after treatment (Snowdon 2002). It has been hypothesized that the length of time that a fertilisation effect is observed depends on the amount of fertilisation applied in relation to the amount of the nutrient on site before fertilisation (Miller 1981). These hypotheses can be evaluated with the models. For each species, sites at three levels of site index were fertilised with $450 \mathrm{~kg} / \mathrm{ha}$ of $\mathrm{N}$ fertiliser at age 50 . This level of fertiliser is generally the maximum that is economically feasible (Barclay and Brix 1985). The percent change in growth as compared to an unfertilised site with the same site index was plotted (part a of Figure 3 is for Douglas-fir; part b is for western hemlock).

The response to fertilisation is much greater for Douglasfir than it is for western hemlock, and the response lasts substantially longer for Douglas-fir. The response and the period of time over which the response is observed decreases as the site index increases. This is likely due to the better sites (as indicated by a higher site index) having a higher store of $\mathrm{N}$ on site at the time of the fertilisation, hence $\mathrm{N}$ is less limiting in growth. A similar response was observed by Heath and Chappell (1989) for Douglas-fir. A few points need to be made with this analysis:

1. Confidence intervals for the predicted percent change in volume growth are not available, so it cannot be determined when the change in volume growth is not significantly different from zero.

2. There is a significant interaction term between fertiliser amount and site index for Douglas-fir (but not western hemlock) and the coefficient for this term is negative (Table 3 , parameter $b_{06}$ ). This results in a predicted loss of volume growth at high levels of fertilisation application and site index. This is more likely an artifact of the modelling than a real response since the predicted loss of growth is small and may not be significantly different from zero.

3. As with all models, users have to be wary when extrapolating these models. The response to fertilisation is extrapolated in terms of the length of the response.

\section{Interaction between fertilisation and thinning}

It may be of interest to determine whether the effects of thinning and fertilisation are additive or if there is an interaction between the two treatments (Miller et al. 1979; Zhang et al. 2005). This can be investigated with the models. The models for both Douglas-fir and western hemlock have significant interaction terms (parameters $b_{04}$ and $b_{24}$ for Douglas-fir, parameter $b_{04}$ only for western hemlock, Table 3). In a much smaller experiment, McWilliams and Thérien (1996) did not find any interaction between thinning and fertilisation in Douglasfir. Simulation was used to investigate how this interaction term affects volume. Three site index levels were assumed with corresponding volumes at age 20 (Table 2) for each species. Thinning and fertilisation treatments $(35 \%$ removal with $450 \mathrm{~kg} / \mathrm{ha}$ urea fertiliser) were applied at age 30. The same scenario was applied with the interaction term removed from the model. The difference in volume is then due to the thinning/fertilisation interaction. The volume-age trajectories are plotted in Figure 4, parts a (Douglas-fir) and b (western hemlock). The effect of the interaction between fertilisation and thinning is slight for Douglas-fir (approximately $20-25 \mathrm{~m}^{3} / \mathrm{ha}$ at age 100 for low and medium sites, practically no difference for high sites) and virtually non-existent for western hemlock. Interestingly, though, the very slight effect of the thinning $\times$ fertilisation interaction for western hemlock is negative which is due to the negative estimated value of parameter $b_{04}$ in Equation 4. The lack of a significant interaction response for western hemlock (even though the parameter for this term is statistically significant) can be attributed to the small estimated value for parameter $\mathrm{b}_{04}$ in Equation 4. When this parameter is multiplied by the thinning and fertilisation effects ( $\mathrm{T}$ and $\mathrm{F}$, respectively, in Equation 4), the term does not have a large effect on the asymptote, particularly as the thinning and fertilisation effects diminish over time.

\section{Comparison to published yield tables}

In this section, the models developed here (Equations $3 / 4$ with appropriate parameters from Table 3) are compared to other published yield tables. For western hemlock, the comparison is made to yield tables published by Barnes (1962) and Taylor (1934). These tables are for 
fully stocked stands with a minimum diameter limit of $1.5 \mathrm{~cm}$, making them approximately the same as the EP703 hemlock plots. However, both of these yield tables are for mixed species stands, and no thinning or fertilisation information is available. Barnes (1962) published yield tables for Oregon/Washington, Alaska, and British Columbia; the British Columbia tables were used in this comparison. At the same starting conditions at age 20, both the Taylor and Barnes yield curves are approximately the same for site index 25 and 29 stands. The western hemlock model predicts greater yields than these two yield tables at site index 25 and 29, but at site index 29 the yields are similar below age 60 . At site index 34, the yields from Equations 3/4 and from Barnes' yield table are almost identical (Taylor did not publish yield tables for site indexes greater than 32).
The fitted Douglas-fir model was compared graphically to published yield tables calculated using the Douglas-fir simulator (DFSIM) (Curtis et al. 1982). The DFSIM is a whole-stand growth and yield model developed specifically for Douglas-fir in the Pacific Northwest region of North America (Curtis et al. 1981). It is able to simulate natural and planted stands with pre-commercial and commercial thinning, as well as fertilisation. Four stand types were compared (natural, planted, planted and commercially thinned, natural with pre-commercial thinning and fertilisation) at three levels of site index $(25.9,32.0$, and 38.1). These correspond to Tables 1, 2, 7, and 11, parts A, B, and $C$ in Curtis et al. (1982). The simulations started at age 30. The starting volumes for the fitted model were taken from the corresponding tables in Curtis et al. (1982). A utilisation limit of $4 \mathrm{~cm}$ (1.6 inches) was used in the comparison
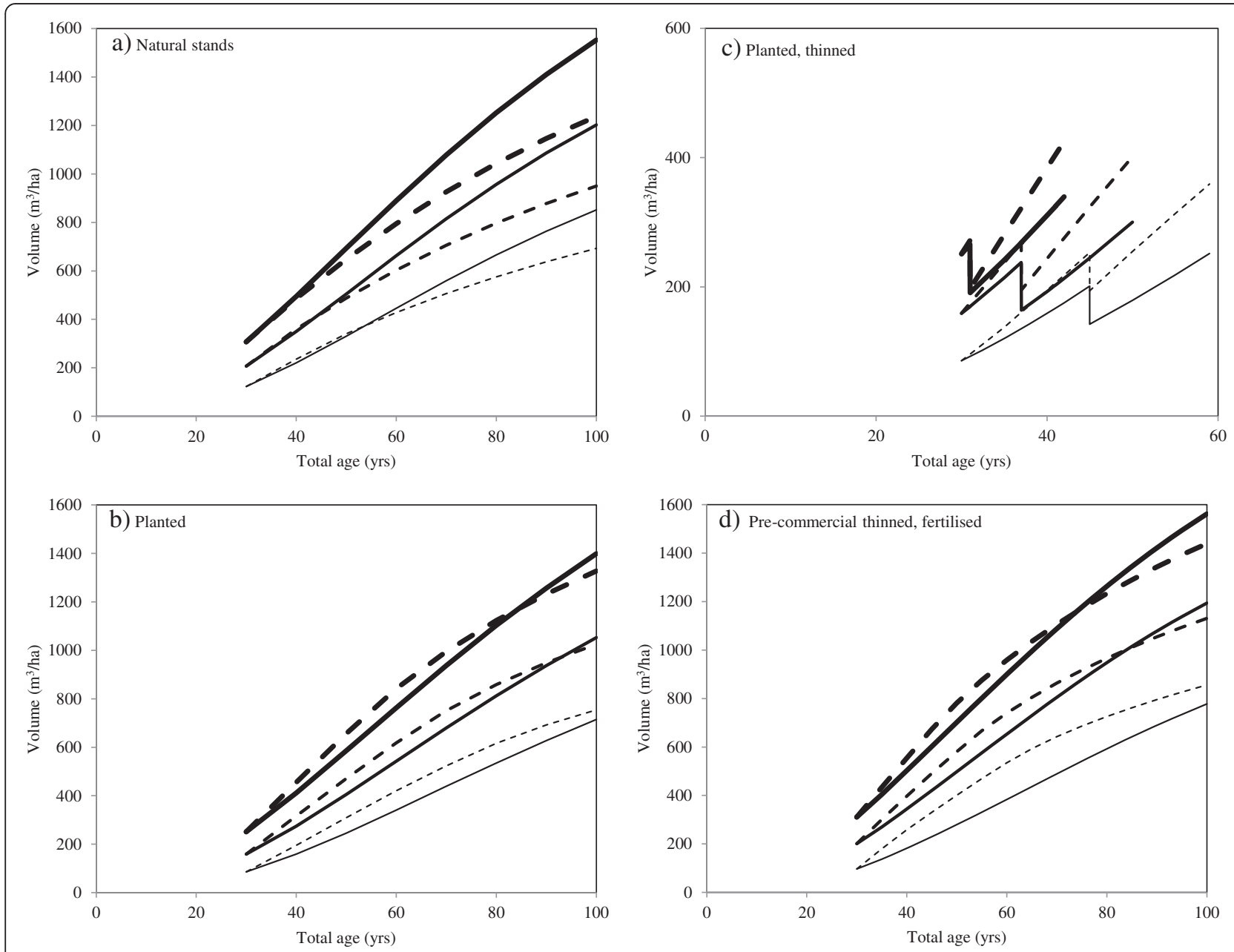

Figure 5 Comparison of Douglas-fir volume estimates from Equations 3/4 to those from DFSIM. Four scenarios were run: Natural stand with no treatments (part a, Tables 1A - 1C in Curtis et al. 1982); Planted to 1000 stems per ha (part b, Tables 2A - 2C in Curtis et al. 1982); Planted to 1000 stems per ha and commercially thinned (part C, Tables 7A - 7C in Curtis et al. 1982); Natural stand pre-commercially thinned and fertilised (part d, Tables 11A - 11C in Curtis et al. 1982). Volume trajectories are shown for Equations 3/4 and DFSIM on a high site (site index = 38.1), medium site (site index $=32.0$ ), and a low site (site index $=25.9$ ). Equations 3/4, low _— Equations 3/4, medium —; Equations 3/4, high 
when more than one utilisation limit was published. The commercial thinning and fertilisation treatments were applied at the same rate and age as in the published tables (Curtis et al. 1982). The thinning removed approximately $30 \%$ of the volume and the fertilisation was done with $225 \mathrm{~kg} / \mathrm{ha}$ of $\mathrm{N}$. The pre-commercial thinning in the fourth scenario was not modelled because the thinning was done too early for the fitted model to have any validity.

Figure 5 parts a $-\mathrm{d}$ show the results of the comparison. For natural stands (part a), there is good correspondence between the two models for the first 20 to 30 years after which the fitted model estimates higher volumes than those estimated by the DFSIM. The deviations between the two models increase with increasing site index. Curtis et al. (1981) had very little data for total ages greater than 60 years even in untreated natural stands. The plantation yield curves (part b) show similar yield projections over the longer term, but again the DFSIM yields are extrapolations beyond about total age 45 (Curtis et al. 1981). Unlike the natural stand yield curves, the differences between the two models decreases as site index increases. Part c shows that use of the DFSIM and Equations 3/4 lead to dissimilar volume predictions for thinning regimes. Both before and after thinning, volume growth rates are greater using the DFSIM model than for Equations $3 / 4$ at all levels of site index, Figure 5c. As noted previously, a slight bias may be present in Equations 3/4 for thinned stands, but not to the extent that it would explain the differences in yield indicated in part $\mathrm{c}$ of Figure 5. The two models may be projecting different populations as there are no data for trees over age 45 in the DFSIM development data set. The fertilisation scenario (part d) shows good agreement between the two models, particularly at higher site indexes. The models developed here do not show as much fertiliser response as the DFSIM at the lower site index level.

\section{Conclusion}

The growth and yield model developed by Nishizono (2010), which is based on the Chapman-Richard's model, was fitted to Douglas-fir and western hemlock data. The resulting models are able to predict responses to thinning and fertilisation. Several modifications were made to Nishizono's model which improved the behaviour of the models. Various scenarios were devised to demonstrate what type of management questions could be answered.

\section{Competing interests}

The author declares that he has no competing interests.

Author's contributions

GN was the primary author and undertook the data extraction and analysis.

\section{Acknowledgements}

Louise de Montigny provided the initial motivation for this research and also has overseen the data collection. Peter Ott and Al Powelson reviewed and earlier draft of this manuscript and gave valuable comments. Louise, Peter, and $\mathrm{Al}$ are with the British Columbia Ministry of Forests, Lands and Natural Resource Operations. Two anonymous reviewers, the Associate Editor, and the Chief Editor also provided valuable review comments.

Received: 20 March 2013 Accepted: 20 August 2013

Published: 28 Aug 2013

\section{References}

Bailey, RL, \& Clutter, JL. (1974). Base-age invariant polymorphic site curves. Forest Science, 20, 155-159.

Barclay, HJ, \& Brix, H. (1985). Effects of high levels of fertilization with urea on growth of thinned and unthinned Douglas-fir stands. Canadian Journal of Forest Research, 15, 730-733.

Barnes, GH (1962). Yield of even-aged stands of western hemlock (U.S.D.A. For. Serv. Tech. Bull. No. 1273).

Bennett, JN, Blevins, LL, Barker, JE, Blevins, DP, \& Prescott, CE. (2003). Increases in tree growth and nutrient supply still apparent 10 to 13 years following fertilization and vegetation control of salal-dominated cedar-hemlock stands on Vancouver Island. Canadian Journal of Forest Research, 33, 1516-1524.

Binkley, D, \& Reid, P. (1985). Long-term increase of nitrogen availability from fertilization of Douglas-fir. Canadian Journal of Forest Research, 15, 723-724.

Brown, K. (2003). Growth and nutritional responses of western hemlock to fertilization: a review. British Columbia Journal of Ecosystem Management, 3, 95-109.

Bruce, D. (1981). Consistent height-growth and growth-rate estimates for remeasured plots. Forest Science, 27, 711-725.

Cañellas, I, del Río, M, Roig, S, \& Montero, G. (2004). Growth response to thinning in Quercus pyrenaica Willd. Coppice stands in Spanish central mountain. Annals of Forest Science, 61, 243-250.

Carmean, WH. (1975). Forest site quality evaluation in the United States. Advances in Agronomy, 27, 209-269.

Chappell, HN, Cole, DW, Gessel, SP, \& Walker, RB. (1991). Forest fertilization research and practice in the Pacific Northwest. Fertilizer Research, 27, 129-140.

Chappell, HN, Omule, SAY, \& Gessel, SP (1992). Fertilization in coastal northwest forests: using response information in developing stand-level tactics. In HN Chappell, GF Weetman, \& RE Miller (Eds.), Forest fertilization: sustaining and improving nutrition and growth of western forests (Inst. For. Resources Contrib. 73, pp. 98-113). Seattle, Wash: Univ. Wash., Coll. For. Resources.

Curtis, RO, Clendenen, GW, \& DeMars, DJ (1981). A new stand simulator for coast Douglas-fir: DFSIM user's guide (U.S.D.A. For. Serv. Gen. Tech. Rep. PNW-128).

Curtis, RO, Clendenen, GW, Reukema, DL, \& DeMars, DJ (1982). Yield tables for managed stands of coast Douglas-fir (U.S.D.A. For. Serv. Gen. Tech. Rep. PNW-135).

D'Amato, AW, Troumbly, SJ, Saunders, MR, Puettmann, KJ, \& Albers, MA. (2011). Growth and survival of Picea glauca following thinning of plantations affected by eastern spruce budworm. Northern Journal of Applied Forestry, $28,72-78$.

Darling, LM, \& Omule, SAY (1989). Extensive studies of fertilizing and thinning coastal Douglas-fir and western hemlock: an establishment report (FRDA Rep. 54). Can. For. Serv. and B.C. Min. For.: Victoria, B.C.

del Río, M, Calama, R, Cañellas, I, Roig, S, \& Montero, G. (2008). Thinning intensity and growth response in SW-European Scots pine stands. Annals of Forest Science, 65, 308. Article number.

Diéguez-Aranda, U, Granda-Aria, JA, Álvarez-González, JG, \& von Gadow, K. (2006). Site quality curves for birch stands in north-western Spain. Silva Fennica, 40, 631-644.

Diggle, PJ, Heagerty, PJ, Liang, K-Y, \& Zeger, SL. (2002). Analysis of longitudinal data (2nd ed.). Toronto, ON: Oxford University Press.

Green, RN, \& Klinka, K. (1994). A field guide for site identification and interpretation for the Vancouver Forest Region (B.C. Min. For., Res. Br., Land Manage. Handb. No. 28).

Heath, LS, \& Chappell, HN (1989). Growth response to fertilization in young Douglas-fir stands. Western Journal of Applied Forestry, 4, 116-119.

Hoyer, GE, \& Swanzy, JD. (1986). Growth and yield of western hemlock in the Pacific Northwest following thinning near the time of initial crown closure (Res. Pap. PNW-365). Portland, OR: U.S. Dep. Agric. For. Serv.

McWilliams, ERG, \& Thérien, G. (1996). Fertilzation and thinning effects on a Douglas-fir ecosystem at Shawnigan Lake: 24-year growth response (FRDA Rep. No. 269). Victoria, B.C: For. Can. And B.C. Min. For. 
Meng, SX, \& Huang, S. (2009). Improved calibration of nonlinear mixed-effects models demonstrated on a height growth function. Forest Science, 55, 238-248.

Miller, HG. (1981). Forest fertilization: some guiding concepts. Forest, $54,157-167$.

Miller, RE, Reukema, DL, \& Williamson, RL (1979). Response to fertilization in thinned and unthinned Douglas-fir stands. In S. P. Gessel, R. M. Kenady, \& W. A. Atkinson (Eds.), Proceedings, forest fertilization conference. Seattle, WA: Univ. Wash. Coll. For Resourc.

Ministry of Forests (1999). Guidelines for developing stand density management regimes. Victoria, B.C: B.C. Min. For., For. Prac. Br.

Ministry of Forests, Lands and Natural Resource Operations (2012). The forest industry snapshot: a selection of monthly economic statistics. Available at: https://www.for.gov.bc.ca/ftp/het/external/!publish/web/snapshot/201203.pdf (Accessed September 21, 2012).

Mitchell, KJ. (1975). Dynamics and simulated yield of Douglas-fir. Forest Science Monographs, 17, 39 .

Mitchell, KJ, \& Cameron, IR. (1985). Managed stand yield tables for coastal Douglasfir: initial density and precommercial thinning (Land Manag. Rep. 31). Victoria, B.C.: B.C. Min. For.

Nishizono, T. (2010). Effects of thinning level and site productivity on age-related changes in stand volume growth can be explained by a single rescaled growth curve. Forest Ecology and Management, 259, 2276-2291.

Pinheiro, JC, \& Bates, D M. (2000). Mixed effects models in S and S-PLUS. New York, NY: Springer-Verlag New York Inc.

Pukkala, T, Miina, J, \& Palahí, M. (2002). Thinning response and thinning bias in a young Scots pine stand. Silva Fennica, 36, 827-840.

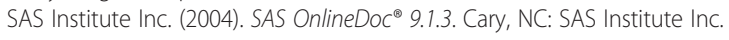

Snowdon, P. (2002). Modeling type 1 and type 2 growth responses in plantations after application of fertilizer or other silvicultural treatments. Forest Research, 163, 229-244.

Reukema, D. L. (1975). Guidelines for precommercial thinning of Douglas-fir (U.S. Dep. Agric. For. Serv. Gen. Tech. Rep. PNW-30).

Richards, F. J. (1959). A flexible growth function for empirical use. Journal of Experimental Botany, 10, 290-300

Sen, AK, \& Srivistava, MS. (1990). Regression analysis theory, methods, and applications. New York, NY: Springer-Verlag New York Inc.

Smith, DM. (1986). The practice of silviculture (8th ed.). Toronto, ON: John Wiley \& Sons.

Spittlehouse, DL. (2003). Water availability, climate change and the growth of Douglas-fir in the Georgia Basin. Canadian Water Resources Journal, 28, 673-688.

Stone, JN. (1994). Extensive studies of fertilizing and thinning coastal Douglas-fir and western hemlock: an installation report (FRDA Rep. 227). Victoria, B.C.: Can. For. Serv. and B.C. Min. For.

Taylor, RF. (1934). Yield of second-growth western hemlock-Sitka spruce stands in southeastern Alaska (U.S.D.A. For. Serv. Tech. Bull. No. 412).

Wiley, KN (1978). Site index tables for western hemlock in the Pacific Northwest (For. Res. Cent. For. Pap. 17). Weyerhauser Co.

Zhang, J, Oliver, WW, \& Powers, RF. (2005). Long-term effects of thinning and fertilization on growth of red fir in northeastern California. Canadian Journal of Forest Research, 35, 1285-1293.

\subsection{6/1179-5395-43-9}

Cite this article as: Nigh: Evaluating Douglas-fir and western hemlock volume growth in response to thinning and fertilisation. New Zealand Journal of Forestry Science 2013, 43:9

\section{Submit your manuscript to a SpringerOpen ${ }^{\circ}$ journal and benefit from:}

- Convenient online submission

- Rigorous peer review

- Immediate publication on acceptance

- Open access: articles freely available online

- High visibility within the field

- Retaining the copyright to your article

Submit your next manuscript at $\gg$ springeropen.com 